\title{
STORIES OF NURSING IN RURAL AOTEAROA: A LANDSCAPE OF CARE
}

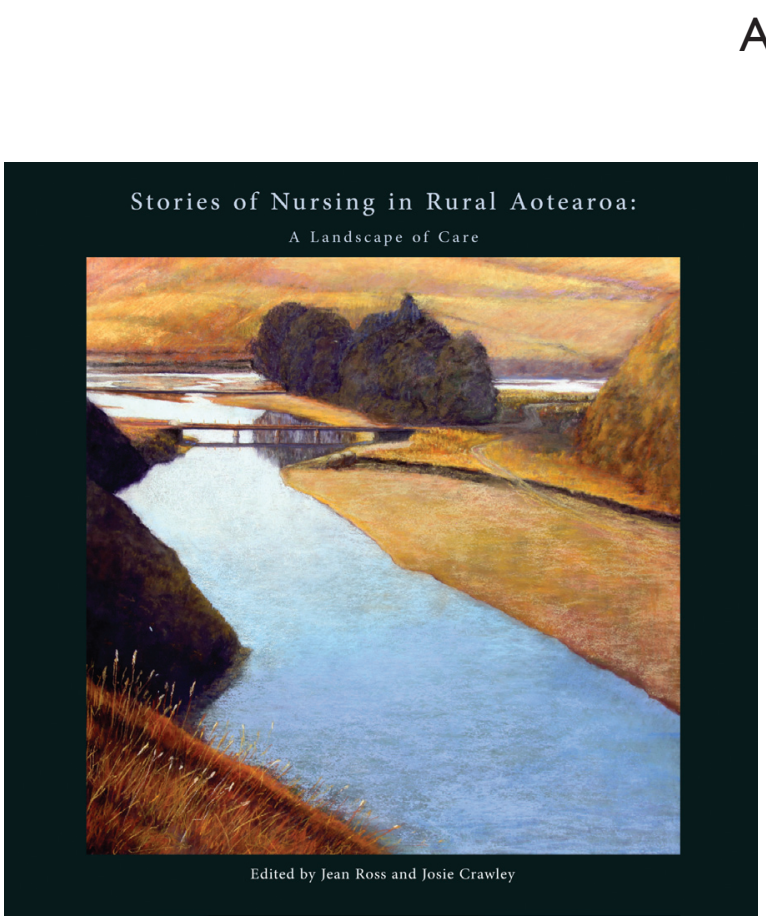

Figure I. J. Ross and J. Crawley (Eds.). (2018). Stories of nursing in rural Aotearoa: A landscape of care.

Dunedin, New Zealand: Rural Health Opportunities.

Stories of nursing in rural Aotearoa: A landscape of care, edited by Jean Ross and Josie Crawley, makes an exceptional contribution to the international rural nursing literature. The textbook is cogently organised, with a preface that presents an overview of the content. The colourful graphics, coupled with personal stories from nurses who live and work in rural and remote New Zealand, offer an exceptional sense of their love for their communities. For one who is not a New Zealand native, the book is much like a travelogue, enticing me to visit this down-under nation. Several unique features are included in this textbook. Especially appealing for each of the chapters is the inclusion of a regional map with scenic photos that feature a particular region of New Zealand. The historical overview at the beginning of a chapter, along with indigenous terminology, folklore and poetry, provides a rich cultural perspective relative to various rural and remote New Zealand regions. The featured rural nurses' stories, including their photos and personal stories, expand the scholarly and professional dimensions of this textbook. The nurses' stories are engaging, interesting to read and expand on the concept of 'place.'The inclusion of numerous footnotes is another useful feature, especially for someone who is not familiar with New Zealand's health-care system. Rather than interrupting a chapter narrative with extensive details, the footnotes expand on relevant historical background and cultural nuances. The authors of Stories of nursing in rural Aotearoa: A landscape of care have made an important contribution to the New Zealand nursing literature and the international rural nursing scholarly community. 
Dr. Angeline Bushy has published and presented widely and is nationally and internationally recognized for her expertise related to rural health and nursing issues. She holds the position of Professor and Bert Fish Eminent Chair at the University of Central Florida College of Nursing.

Correspondence to: Angeline Bushy, Daytona Beach Regional Campus, Florida, USA. Email: angeline.bushy@ucf.edu 